\title{
Fashion Photography on Social Media: Insights from Hong Kong Fashion Image Producers
}

\author{
Athena Choi \\ Department of Fashion and Image Design, \\ Hong Kong Design Institute, Hong Kong
}

\begin{abstract}
:
This study draws on fashion and culture theories to explore the influence of visual sharing culture on social media in fashion. The objective is to interpret the perceived creative values and the meanings of such cultural phenomenon from the perspective of fashion media industry in Hong Kong. In-depth interviews, in the exploratory semi-structured format, were adopted in which 20 fashion image producers in Hong Kong were interviewed regarding their increasing involvement in professional fashion image making and blogging. Among the 20 respondents, 12 respondents were younger generation of image producers with experience around 3 years, while 8 respondents have been in the industry for 15 years in average. The findings of this research indicated that the nature of visual oriented social media platform supports a new communication model between the new generation of fashion image producers and image audience. It is evident that there is a new trend for young fashion lovers to become successfully engaged in the industry as career bloggers who can create their styles and express their ideas through fashion imaging and sharing. On the other side, the professionalism and authenticity of the young generation of fashion bloggers are sometimes in questions. The finding is significant to further academic studies on the value of fashion visual communication on social media, and to business sectors, in which this study provides insight for young fashion lovers for career development.
\end{abstract}

Paper Type: Research paper

Keywords: Social Media, Fashion Blogs, Fashion Media, Fashion Photography, Hong Kong, Creative Value 


\section{Introduction}

With the proliferation of web 2.0 technology, social media becomes a popular platform for young fashion lovers to express themselves by creating and sharing their own fashion photographic images. The omnipresent fashion photographic images on social media have become an influential power that challenges the traditional hierarchy of fashion media communication. In the traditional model of fashion media communication, professional production of fashion photography holds a predominant position in fashion leadership, trend diffusion, and brand promotion (Jobling, 1999). While previous studies suggested that social media 'democratizes' fashion world (Pham, 2011; Rocamora, 2013), the relationship between fashion brands and fashion bloggers becomes more interdependent as popularity of blogging continues to grow. A career pathway has also emerged for successful bloggers (Mcquarrie, et al, 2012; Pihl and Sandstrom, 2013). Given the essential role of fashion photography on the visual presentation of fashion, there is surprisingly very few academic research dedicated to the investigation of the value created by fashion photography. Today, technology advancement seems to jeopardize the future of professional fashion photography, what will be next in the fashion image production genre remains unclear. The objective of this study is to interpret the perceived creative values and the meanings of such phenomenon from the perspective of fashion media industry in Hong Kong. The finding aims to construct a new model of how fashion bloggers seize the opportunity in the social media in the Hong Kong fashion media industry.

The paper is organized as follows. First, recent literature on fashion photography, social media, fashion blogging, is reviewed and presented in section 2. following to that, methodology is discussed in section 3 and the analysis approach in theoretical development is explained in section 4 . The findings are reported in section 5 , and finally section 6 discusses the results and conclusion of the paper.

\section{Literature Review}

While fashion is a popular topic in academic research, the area of fashion photography receives very limited attention in previous studies. In order to understand the changing genre of fashion photography in the digital age, this literature review section will begin with an overview of studies related to fashion photography, and follow with the recent development of social media focusing on fashion blogging.

\subsection{Study on Fashion photography}

Fashion photography is defined as the len-based production of a photographic image containing fashion products. Fashion photography exists since the invention of camera, and performs the essential function of presenting fashion products for commercial purpose (Hall-Duncan, 1977; Jobling, 1999). The terms fashion photography, fashion images, fashion shots are used interchangeably in the fashion industry, and will also be adopted in this study.

Despite the essential function of fashion presentation and the value of media communication to consumers, fashion photography appears to be a relatively neglected segment among numerous academic studies on fashion (Shinkle, 2008; William, 1998;

International Journal of Management and Applied Research, 2016, Vol. 3, No. 4 
Derrick, 2002). Perhaps Hall-Duncan's (1977) the History of fashion photography is considered one of the most comprehensive documentaries on the historical development of fashion photography for the last century (Jobling, 1999; Williams, 2008). Studies on fashion photography were often blend-in with academic studies as the research tool rather than the core research subject. For example, numerous studies took fashion photography as the tool to investigate the response of readers on advertising message (Bailey and Seock, 2010; Gulas and McKeage, 2000; Ivas, 2002; Philips and McQuarrie, 2010), relatively few research focused on the visual interpretation of fashion photography itself (de Perthuis, 2005; Hartley and Rennie, 2004; William, 2008). Shinkle (2008) argued that fashion photography has significant value to the society, echoing Hall-Duncan (1977) that fashion photography processed in itself the artistic integrity, social importance, and cultural implications. In an agreement to the work of Hall-Duncan in 1977, Jobling (1999: p. 3) suggested that the visual representation of fashion photography goes beyond the simple purpose of selling clothes, but to create fantasies, and a "profound impact on the social and cultural scene."

\subsection{Social media and digital culture}

Since its launch in the nineties, the social media has grown in an accelerated rate. In the beginning, it was an online interactive system linking individual users to form a social network, and such uniqueness gained its original terms including computer mediating communication (CMC) and social networking sites (SNS) (Boyd and Ellison, 2007; Kaplan and Haenlein, 2010). Since the system enables users to present themselves with another identity, the launch of social media induced growing interests from cultural theorists on the discussion on identity and representation (Lovint, 2011). The rise of social media is often considered a realization of various predictions in digital culture theories in the early nineties.

One of the most prominent changes created by the digital culture was the communication pathway from one way directional to networked multi-directions. The work of Poster (1995) has been considered one of the first scholarly studies on the theories framing the emerging phenomenon of digital media communication (Miller, 2011). He argued that the new media of internet has reformed the traditional broadcast one-directional model to a multi-directional model of the internet. Poster's model has been proven to be prophetic in principle. Two decades later, his model still resembles in similarity with various media analysts conclusion on social media communication and illustrates the diffusion structure of media systems (Athique, 2013). The implication of such change restructured the hierarchy system between message senders and audience. In the traditional model, the media are controlled by a small group of elite members in the society who seize the power at the top of hierarchy system. This notion challenged the Frankfurt school's philosophers such as Adorno and Horkheimer (1991) in the critique of modernity in media influence, where the one way diffusion model of media communication promotes passive audience as the message receivers. By contrast, new media model of social media breaks down the hegemony of media diffusion, and changes to a networked communication system (Athique, 2013; Miller, 2011; Levy, 2001).

International Journal of Management and Applied Research, 2016, Vol. 3, No. 4 


\subsection{Fashion blogging as the new digital culture}

Today fashion bloggers normally diversify their exposure by managing a network of image sharing social media platforms including blog, Facebook, Twitter, Instagram, Tumblr, or Pinterest. Therefore, this study uses the term 'fashion blogging' to refer to the activity of presenting fashion shots using various social media platforms as a networked medium, and the term 'fashion blogger' refers to the host of fashion image producers using all these platforms. Given the visual based free access nature, fashion blog has become a popular platform nurturing numerous fashion lovers, mostly teenagers, to express their identities, tastes, sharing of their fashion photos, and giving them the opportunity to act as 'citizen journalists' (Pham, 2013, Huffaker and Calvert, 2005). A few of these teenagers such as Susie Bubble, Bryant Boy, had turned from ordinary teenagers to internationally renowned fashion celebrities and key opinion leaders (KOL) (Griffith, 2011; Pham, 2013; Rocamora, 2013). Fashion blogs changed fashion leadership of trend diffusion, consumers' response to fashion images, and perception on individual fashion image creators (Pederson, 2011).

One of the popular social media research areas from cultural perspective was the influence of fashion blogs on teen's identity (Chittenden, 2010). There was also anticipated change in authorship of fashion news in the future (Pederson, 2011). A completely new theory was suggested to address the relationship between the media and viewers (Manovich, 2002). Fashion bloggers take bloggings as their platform of self and artistic expression, the feature of interaction enabling bloggers to express themselves and construct identity on a new form of 'public space' (Chittenden, 2010; Kietzmann, et al, 2011; Rocamora, 2011). These fashion bloggers, amateur in professional image making, create their own fashion styles, photograph themselves and share online regularly and act as a form of self-expression. Chittenden (2010) drew on Bourdieu's theory to examine teenage fashion bloggers exchanging cultural and social capital in order to develop their own identities through the online space. Hence, fashion blogs perform as a means of visual representation carrying specific 'code' of a field. This visual display, in a form of fashion photography, becomes teenage blogger's cultural capital (Chittenden, 2010; Rocamora, 2011; McQuarrie et al, 2012). Bloggers accumulated followers by displaying taste leadership from their own fashion styles (McQuarrie et al, 2012). This notion echoes a similar view of the 'Celebrity self' proposed by Marwick (2013). Displaying fashion tastes functions as a form of self-presentation to achieve a status of 'micro celebrity'. Marwick termed this 'the celebrity self' and described the process of how bloggers create online status achievement, and develop themselves as a branding process (Marwick, 2013).

While studies focus on cultural interpretation on fashion blogging generally agree on the identity construction and linkage in taste leadership, there seems to be less attention on how fashion bloggers actually benefit in economic turn from achieving this activity. Phil and Sandstorm's study (2013) indicated the importance for individual citizen journalists to strike the balance between commercial and personalized contents if they are trying to achieve financial gain by self-branding process. Hence, further research gap is opened for drawing on these research directions to formulate a new interpretation of fashion media communication in Hong Kong.

International Journal of Management and Applied Research, 2016, Vol. 3, No. 4 


\section{Method}

In-depth interviewing was identified for this research, as the research aims to investigate the underlying attitude, preference or perception of the impact of social media on fashion photography, the approach of in-depth interviewing could enable the flexibility and the depth of the understanding of the research objectives (Collins, 2010; Gillham, 2005). This study was based on semi-structure interviews with open-ended questions on respondents' view on the current trend of fashion blogging. 20 participants were identified from researcher's personal connection with Hong Kong fashion industry's practitioners. 12 of the respondents are young fashion image creators with college education in fashion related discipline, at age around mid-twenty; their working experiences ranged from 2 to 4 years. 8 respondents are experienced professional fashion image creators with an average of 15 years of working experience. All of them have participated in commercial fashion shooting in different roles such as stylists, editors/reporters, or photographers. Each of them is familiar with social media and engages in certain level of readership on fashion images through social media. Table 1 shows the list of the profile of respondents and their work experience.

Table 1: Profile of respondents in Hong Kong fashion media industry

\begin{tabular}{llc}
\hline Job Title & Nature of the employed company & $\begin{array}{c}\text { Year of work } \\
\text { experience }\end{array}$ \\
\hline Fashion reporter & Local fashion magazine & 3 \\
Fashion reporter & Local fashion magazine & 3 \\
Fashion stylist & Self-employed, various fashion clients & 3 \\
Fashion photographer & Self-employed, various fashion clients & 3 \\
Assistant costume designer & Hong Kong film's production and fashion clients & 3 \\
Assistant photographer & International fashion magazine, Hong Kong edition & 3 \\
Stylist intern & International fashion magazine, Hong Kong edition & 2 \\
Fashion editor & Local fashion magazine & 3 \\
Fashion stylist & Self-employed, various fashion clients & 4 \\
Fashion stylist and make-up & Various fashion clients & 4 \\
artist & & 2 \\
Fashion reporter & Local newspaper's fashion supplement & 2 \\
Fashion reporter & Local fashion magazine & 20 \\
Fashion photographer & Self-employed, various fashion clients & 20 \\
Fashion public relations director & Local fashion magazine & 10 \\
Fashion photographer & Local fashion magazine & 20 \\
Fashion photographer & Owner of photography company & 20 \\
Fashion photographer & Owner of photography company & 15 \\
Fashion photographer & Self-employed, various fashion clients & 10 \\
Executive editor & Local fashion magazine & 10 \\
Fashion photographer & Self-employed, various fashion clients & 3 \\
\hline
\end{tabular}

With the actual names disguised, each interviewee was well informed of the research purpose and volunteered to join, no specific concern of confidentiality was raised because no specific question was personal, and the interviewees could express in comfort regarding their view on fashion photography and social media. Hence, consideration of research ethics in confidentiality and anonymity was taken into account (Rose, 2012; Oliver, 2010).

International Journal of Management and Applied Research, 2016, Vol. 3, No. 4 


\section{Data analysis}

The data of the interviews was analyzed by inductive approach. Coding strategy was a two-level coding according to the principle by Miles and Huberman (1994, p. 69). The $1^{\text {st }}$ level of coding is used to summarize segments of primary data according to the research objectives. The second level of coding refers to Pattern coding, which aims to categorize the $1^{\text {st }}$ level codes into several themes or concepts. As the study progressed along in inductive approach, the empirical data emerged new insights, and the list of codes was then reviewed and revisited again during the data analysis process, and finally a structure of $2^{\text {nd }}$ level pattern codes was redefined. This followed the research process suggested by Lincoln and Guba (1985), the list of the codes has been re-constructed according to the four steps 'filing in', 'extension', 'bridging' and 'surfacing'. The codes were reconfigurated into the level 2 of emerging concepts (pattern codes) for further integration of conceptual themes. Each of the data coding of 1st level coding and 2nd level of categorization are listed in Table 2, 3, and 4 as below. The findings are discussed in details in next section.

\section{Findings and Discussion}

This section begins with the finding of the overview of Hong Kong fashion media industry, and follows by the discussion of emerged conceptual themes on the fashion images on social media. A summary of findings and discussion will be provided at the end of this section.

\subsection{Hong Kong fashion media market}

The interviews began with discussion on the mechanism of the image creation in Hong Kong fashion media, where traditional printed magazines are still the mainstream of current production sites for fashion photography. Majority of the respondents are still active in engaging different creative roles in fashion photography. Respondents revealed that a hierarchy exists in the fashion image production process that influence visual content and production output of the fashion photography, there is always a power negotiation between stakeholders such as the brand owners, designers, and company investors in terms of the expectation of the visual elements. The creative team, including fashion photographers, stylists, fashion editors, performs as the change agent and the producers of the image. Respondents observed that there are changes in perceived values on aesthetics, professional knowledge and technical skill to the fashion communication system under the culture of social media.

A common observation emerged for the overall view on fashion media industry in Hong Kong is that the market for tradition printed media is shrinking, but it would not be totally replaced by online media. The tightened advertising budget from fashion industry enables an opportunity to nurture the growth of fashion blogging. Compared to the huge budget in producing advertising images, the sponsorship for fashion bloggers is considered much cost effective to fashion brands. Much of the discussion focused on the perceived values on these fashion images created by bloggers in comparison with the fashion photography produced by professional team.

The market situation is chaotic now, the future [for professional fashion

International Journal of Management and Applied Research, 2016, Vol. 3, No. 4 
image producers] would depend on whether one could seize the opportunity in the new environment of social media. (Respondent K, Line 28)

I believe that there is still room for Hong Kong fashion media industry. As fashion media houses are generally small scale in Hong Kong, the image production budget is limited. Media houses may shift the budget to sponsor fashion bloggers to sell clothes. This fits well in our market situation, instead of investing large amount of budget to do fashion advertising shooting, investing in fashion bloggers may be more cost effective for fashion brands. (Respondent I, Line 94)

\subsection{Conceptual Themes}

In terms of the fashion content on social media, respondents indicated that the nature of Hong Kong fashion media market favors more on an image based content. The finding shows that three conceptual themes were emerged from the 2 nd level of concept categorization. The three conceptual themes of value creation are: $1 /$ identity expression, 2/ artistic expression, and 3/ trend diffusion. These three concepts of value creation form a self-branding process in the fashion communication model. Hence, a new communication model of fashion blogging has emerged in the Hong Kong fashion media industry. Each of the conceptual theme is elaborated according to the breakdown of 2 nd level categorizations and is discussed in details as follows:

\subsubsection{Conceptual Theme 1: Identity Expression}

Table 2: Conceptual Theme 1: Identity Expression

\begin{tabular}{lll}
\hline 1st level Coding & Code Descriptions & 2nd level: Categorization: Concept development \\
SE-ATTD & Attention drawing & \\
SE-IND & Individual angle & \\
SE-CONS & Consistency & \\
SE-SLIFE & Share lifestyle & \\
SE-PROM & Self promotion & \\
SE-STY & Special style & \\
SE-BRN & Brand endorsement & \\
& & 1. an open space for 'the creative self' \\
& & 2. aspiration for other producers \\
& & 3. identity empowerment by authority \\
\hline
\end{tabular}

\subsubsection{An opening space for 'the creative self'}

Respondents expressed that the nature of a networked free entry public space provides a sharing display platform for amateur image producers (Chittenden, 2010; Rocamora, 2013). Unlike traditional fashion media, where one will face rigorous competition in order to enter the industry, social media allows everyone to exhibit their own creative works such as fashion images. There is no constraint of the content in relationship to the context of the medium and the consideration of stakeholders, fashion trends, or else. The images posted on social media could be purely personal or alternative, but the key successful element is to establish a personal style consistently (McQuarrie et al, 2012). Although the notion of 'identity construction' is not a new discourse in the digital culture (Miller, 2011), the identity expression of this finding suggests a fashion specific image creation of the self rather than a 'narrative self' described by scholars. This finding indicates a networked space for the exhibition of a fashionable representation of the self. Image producers take advantage of this nature to express a 'creative self' by the self-production of fashion photography of users. This notion of 
'creative self' is similar to the 'celebrity self' coined by Marwick (2013) in way of presenting an interactive fans and celebrity relationship, by achieving this, the celebrity self focuses on self-commodification in order to create a 'publicizable personality'. On the other side, the creative self differs from the celebrity self in terms of a holistic branding strategic that the bloggers input.

Yes, [social media] enables people to have their own platform, unlike websites, the [Instagram] system could check readership, and even fashion editors need to adapt to this trend [blogging]. (Respondent C, Line 81)

\subsubsection{Aspiration for other image producers}

The younger generation of respondents tends to read other fashion blogger's images for self-reference. They compare their own works to the well-known bloggers, and try to learn from those bloggers' successful tactics. Younger respondents indicated that they will examine why the bloggers gain popularity on social media. Their observations concluded some common traits. Besides the visual elements, bloggers who accumulate substantial number of followers and 'like' are generally those who input much effort in running the account like a business. 'It is actually a full time job', respondents remarked. There is certain period of time during the day for posting images to gain more 'like'. Other tactics to gain popularity include the effective use of hashtag '\#' function on Instagram, following other accounts with similar style, and 'follow for follow' function. In addition, Bloggers' real life social network also helps in spreading the account name. Hence, social media acts as a reference of aspiration for young generation of fashion image makers who wish to participate in fashion blogging as a stepping stone to enter the industry.

As a person who works in fashion media, what I am looking for is different from the mass market. I look at the ways the successful bloggers try different things... and to know what they have been up to...to know what events they go...the world they present seems to be really interesting. (Respondent I, Line 50)

\subsubsection{Identity empowerment by authority}

Respondents suggested that the ultimate success of fashion blogging is relied on the recognition of the authority of fashion industry. These authority figures include fashion editors of key leading fashion magazines, fashion designers, or fashion directors of famous brands. The power game in the fashion system appears to be changing in the phenomenon of social media culture. Bloggers need to be endorsed by authority in the hierarchy of the fashion world to become significant icons. This reflects a self-branding process to gain a 'fashion identity'. The new system of social media breaks the traditional hierarchy in fashion system. Bloggers and fashion industry leaders established a mutual interdependent relationship (Phil and Sandstorm, 2013). Fashion brands and media public relationship representatives (PR) are aware of the powerful readership led by bloggers, and at the same time, bloggers gain access to the fashion industry by constantly posting fashion photographs and accumulating the numbers of followers base.

I believe that in order to be considered successful, bloggers need to be

International Journal of Management and Applied Research, 2016, Vol. 3, No. 4 
recognised by the powerful people in the fashion world. (Respondent $\mathrm{P}$, Line 26)

The implications of the above findings suggest three aspects of identity expression for fashion photography. First, social media provides an open space for users to construct a creative self. Next, successful bloggers' images become the aspiration for other image producers. Finally, what remains powerful behind this media communication hierarchy still relies on the authority in the fashion industry, but the pathway resembles an interdependent relationship between the self-branding individuals and fashion brands.

\subsection{Conceptual Theme 2: Artistic Expression}

Table 3: Conceptual Theme 2 Artistic Expression

\begin{tabular}{lll}
\hline 1st level Coding & Code Descriptions & 2nd level: Categorization: Concept development \\
AE-BKGD & Background location & \\
AE-COL & Color tone \\
AE-MOOD & Mood \\
AE-ANG & Angle \\
AE-STY & Style \\
AE-COMP & Composition \\
AE-CREV & Creative Concept \\
AE-MODEL & Model
\end{tabular}

1. The expectation: The professionalism of blogging

2. The expectation: 'Value-adding' in alternative taste leadership

\subsubsection{The expectation: The professionalism of blogging}

In general, respondents questioned the professionalism of bloggers in presenting the fashion information or the production quality of the fashion photography. In the culture of social media, the importance of popularity overrides professionalism. Since it is a free entry for social media, everyone can post their images online. Readers seem to hold a hidden consensus that the professionalism of users-turn-producers may not be the first priority. Readers will not expect in-depth information on social media as they only spend a few seconds to browse the images. Given the tiny screen on the mobile phone, together with the help of photo retouch device, it is much easier to tune the photos to become more moody or stylish. Therefore, as respondents referred, they tend to be more 'tolerant' to the lower quality of the fashion photography. What matters most is whether the content of the image interests readers, this could be the overall fashion style, the mood of the photos, the background, or the event that shown in the images.

When we look at fashion images on social media, we are more tolerant towards the lower professionalism of the photographic quality; whereas for magazines, we expect a professional standard. Because in social media, bloggers are just posting their snap shots, we can accept the imperfect way of doing fashion presentation. (Respondent L, Line 65)

\subsubsection{The expectation: 'Value-adding' in alternative taste leadership}

International Journal of Management and Applied Research, 2016, Vol. 3, No. 4 
Respondents observed that there are two layers of information presented from fashion bloggers, 'gathering information' and 'offering things to sell'. According to respondents, just 'gathering information' could not satisfy readers. If the bloggers just copy the whole set of fashion styling outfits from fashion brands and put on themselves, this is considered 'boring' and no value-added insight offered. Hence, the concept 'value-adding' is emerged. Generally bloggers who could differentiate themselves in offering alternative tastes different from mainstream are considered more valuable. Readers look for alternative in various aspects from the images produced by fashion bloggers, this could be alternative fashion style, aesthetic presentation, or the alternative appearance different from traditional fashion media.

The above findings suggest that artistic expression of fashion photography has been altered in a way of the changing expectation towards the professionalism of fashion bloggers, and there are other value-adding expectation such as the alternative taste leadership.

\subsection{Conceptual Theme 3: Clustering trend diffusion}

Table 4: Conceptual Theme 3: Clustering trend diffusion

\begin{tabular}{lll}
\hline 1st level Coding & Code Descriptions & 2nd level Categorization: Concept development \\
TS-FAST & Fastest \\
TS-MAPP & More approachable & \\
TS-REF & Style Reference & \\
TS-NEWT & Notice of new trends \\
TS-FILT & Filter trends & \\
TS-BRD & Push by brands & 1. Clustering of trend diffusion \\
\hline
\end{tabular}

\subsubsection{Clustering of trend diffusion}

Social media not only brings the high fashion to the mass market faster, but also allows alternative fashion styles diffuse as a trend. In the past, what fashion trend diffusion matters is the mainstream fashion style. Social media provides a public space for alternative styles to be displayed. Respondents agreed that there is still a mainstream hierarchy model in fashion trend diffusion (McCracken, 1985), where social media accelerates the diffusion rate in the trickle down process (McQuarrie et al, 2012). However, the influence of the mainstream top down model diminishes nowadays in the digital age, respondents observed that there is no obvious or dominant fashion trend in Hong Kong. Rather, fashion readers take autonomy in identifying their own preference from social media images, and forming clusters of style community. This phenomenon echoes Poster's (1995) communication model in scattered clusters instead of directional trends. Therefore, this finding suggests that a new pattern of clustering in fashion trend diffusion has emerged.

People can identify the trend easier through blogs. The trend in Hong Kong changes too quickly, it is hard to find a particular style trend now. I do not see a particular direction. But social media has a powerful strength in a way that it is faster than any other channels. (Respondent K, Line 67)

\subsection{Summary of findings and discussion}

The findings of this study reveal that the rise of social media creates both challenges

International Journal of Management and Applied Research, 2016, Vol. 3, No. 4 
and opportunities for the fashion media industry. It is predicted that the overall fashion media industry is shrinking, and therefore imposes challenges to the traditional fashion image production business. On the other side, the new platform of social media allows fashion brands to shift the tightened budget for image production in the form of fashion blogging. The new digital culture alters the perceived values on fashion photography on artistic expression, fashion trends and tastes, these changes enable new comers to join the fashion industry through a self-branding process.

The emerged three conceptual themes provide interpretation of a new genre of fashion photography on social media in three aspects, 1/ identity expression, 2/artistic expression, and $3 /$ clustering trend diffusion. The visual sharing nature enables a direct communication between image producers, image audience and fashion brands. The unique nature of fashion blogs to display the 'creative self' eventually enables individual citizen journalists to gain entry to the fashion industry (Pham, 2011), and thus blurring the idea of self identity and brand identity of the blogger's self. Instead of terming identity building, this process is rather an identification process in the digital culture (Miller, 2011). The bloggers are they own brands (Pihl and Sandstorm, 2013). The finding reveals that self-branding is essentially empowered by the authority in the fashion world.

Respondents also observe that blogger carefully calculates the tactics when constructing the personal blogging business. As the trend evolves in proliferated speed, the competition for amateur bloggers in the fashion field becomes more rigorous. Bloggers need to establish a unique identity, and accomplish a status of fashion icon through calculated self-branding strategy by identity construction. Meanwhile, the new perception on artistic expression and trend diffusion contributes as the two key factors to reinforce the self-branding process. The expectation of fashion photography on social media has shifted from professional production value to individualized content. The diversity in various styles has also altered fashion trend diffusion in a clustering pattern. On the other side, the overwhelming images available on social media redefine aesthetic concept on the judgment of visual component in fashion images and alternative taste. The overwhelming display of highly individualized images may sometimes generate negative response. The professionalism of fashion blogging would also be in doubt.

In order to establish 'the creative self', bloggers work in collaboration to achieve professionalism in photo shooting, image styling, hair and make-up, lighting, set up etc. With the establishment of 'creative self', fashion bloggers present themselves as fashion icons and gain attention of followers and 'like' through calculated tactics of accumulating popularity. By doing this, fashion bloggers work more similarity to a way of self-branding approach (Marwick, 2013), and breaking down the institutionalized mechanism in the commercial hierarchy of the fashion media. Hence, a new model of blogger's self-branding process is constructed (Figure 1). This model contributes to both academic and business sectors in several ways. For academic sector, this model presents a new framework to interpret the phenomenon of fashion blogging and lays a foundation for further study related to digital fashion communications. In terms of commercial sector, the model serves to provide insights for young fashion lovers on the tactics of career development in the new digital culture of fashion 
blogging.

Figure 1: Fashion Bloggers' self-branding model (constructed by researcher)

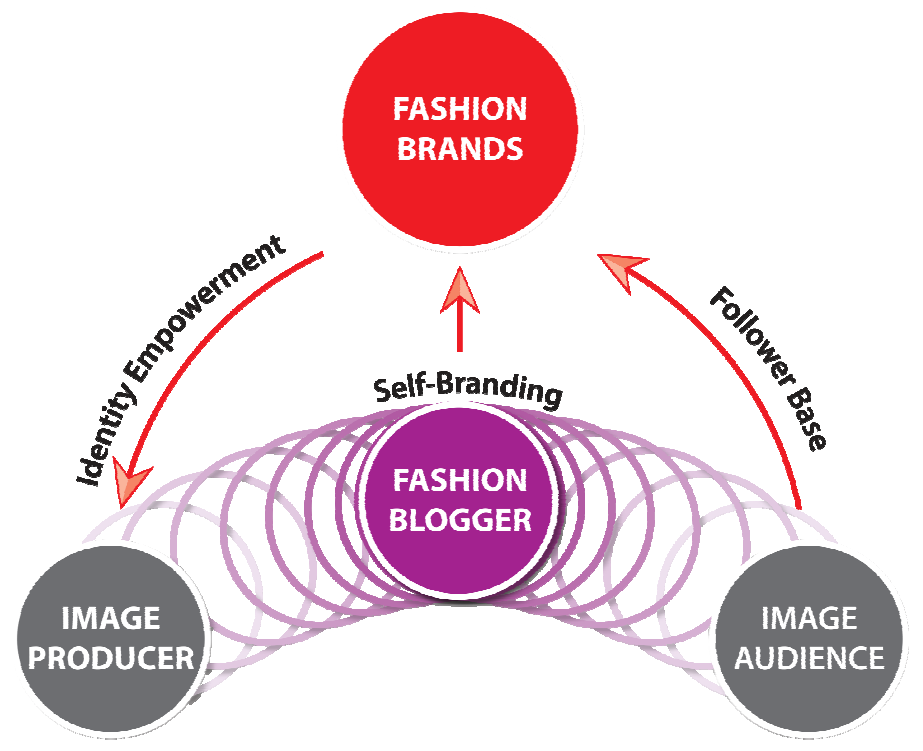

\section{Conclusion}

This study adopted in-depth interview for fashion image producers in Hong Kong to investigate the impact of social media on fashion photography. The results provide a qualitative measure on the perceived creative values of fashion photography in the digital culture, and practical insights for the fashion media industry in Hong Kong.

The results of this study suggest that the rise of social media induces both new opportunity and challenge for fashion media industry of Hong Kong. This study argues that social media has altered the expectation in artistic expression and trend diffusion in the fashion industry. There is an opportunity arise for young fashion lovers to gain access to the fashion industry by engaging the activity of fashion blogging. Fashion bloggers seize a unique position in the fashion image media industry, in which a new model of fashion bloggers' self-branding process is constructed. On the other side, professionalism of fashion photography is often in doubt under the new culture of social media.

This study has several implications for the professional image producers, fashion bloggers and fashion brands in Hong Kong. First, this study indicates a challenge to the professional image producers in Hong Kong fashion media industry. It is essential that professional image producers could adapt to the new form of image sharing culture in order to sustain their career in the media industry. Secondly, this study provides insight for fashion bloggers on progressing from building self-identity to self-branding as a career pathway to join the fashion industry, particularly in the context of Hong Kong fashion media scenario. Lastly, it is suggested that fashion brands should be aware of the perceived alternative taste leadership and artistic

International Journal of Management and Applied Research, 2016, Vol. 3, No. 4 
expression when promoting the brands. At the same time, they should be cautious about the potential negative response towards overwhelming images on social media.

There is also limitation for this study. This study only investigates on one dimension of the topic from the image producers' perspective. Since the creative values would be perceived differently from image producers and image audience. The findings may be limited to the opinion from the side of image producers and neglect the views from image audience. Further recommendation for this study is to investigate audience's reception on the images posted on social media, so that the perceived values are comparable between image producers and image audience of fashion photography.

\section{References}

1. Adorno, T. and Horkheimer, M. (1991), The Culture Industry: Selected Essays on Mass Culture, London: Routledge.

2. Athique, A. (2013), Digital media and society, An Introduction. Cambridge: Polity Press.

3. Bailey, L. and Seock, Y. (2010), "The relationships of fashion leadership, fashion magazine content and loyalty tendency", Journal of Fashion Marketing and Management, Vol. 14, No. 1, pp 39-57. https://doi.org/10.1108/13612021011025429

4. Bourdieu, P. (1993), The field of cultural production: essays on art and literature. Cambridge: Polity Press.

5. Boyd, B and Ellison, N (2007), "Social Network Sites: Definition, History, and Scholarship", Journal of Computer-Mediated Communication, Vol. 13, No. 1, pp 210-230. https://doi.org/10.1111/j.1083-6101.2007.00393.x

6. Chittenden, T. (2010), "Digital dressing up: modelling female teen identity in the discursive spaces of the fashion blogsphere", Journal of Youth Studies, Vol. 13, No. 4, pp. 505-520. https://doi.org/10.1080/13676260903520902

7. Collins, H (2010), Creative Research: The Theory and Practice of Research for the Creative Industries, Case Postale: AVA Publishing SA.

8. de Perthuis, K. (2005), "The Synthetic Ideal: the Fashion Model and Photographic Manipulation", Fashion Theory. Vol. 9, No. 4, pp. 407-424. https://doi.org/ $10.2752 / 136270405778051149$

9. Derrick, R. (2002), “The Cinderella Syndrome”, In: Derrick, R. and Muir, R. (ed.), Unseen Vogue: The Secret History of Fashion Photography. London: Little, Brown. pp 8-9.

10. Gillham, B. (2005), Research Interviewing: The range of techniques. Berkshire: Open University Press.

11. Griffith, E. (2011), "Bloggers Mean Business", Adweek. [Online] Available from: http://www.adweek.com/news/advertising-branding/bloggers-mean-business-1347 $\underline{57}$ [accessed on 19 September 2016].

12. Gulas, C.S. and McKeage, K. (2000), "Extending Social Comparison: An 
Examination of the Unintended Consequences of Idealized Advertising Imagery", Journal of Advertising, Vol. 29, No 2, pp 17-27. https://doi.org/10.1080/00913367.2000.10673606

13. Hall-Duncan, N. (1977), The History of Fashion Photography. New York: Alpine Book Company

14. Hartley, J. and Rennie, E. (2004), “About a Girl': Fashion photography as photojournalism”, Journalism, Vol. 5, No. 4, pp 458-479. https://doi.org/10.1177/1464884904044205

15. Huffaker, D.A. and Calvert, S.L. (2005), "Gender, identity, and language use in teenage blogs", Journal of Computer-Mediated Communication, Vol. 10, No. 2, pp 00. https://doi.org/10.1111/j.1083-6101.2005.tb00238.x

16. Ivas, L. (2002), "Female - a prop: using the female body as a sales tool in advertising", paper presented at the International Textile and Apparel Association Annual Meeting, New York.

17. Jobling, P. (1999), Fashion spreads: word and image in fashion photography since 1980. Oxford: Berg.

18. Kaplan, A.M., and Haenlein, M. (2010), "Users of the world, unite! The challenges and opportunities of Social Media”, Business Horizons, Vol. 53, No. 1, pp. 59-68. https://doi.org/10.1016/j.bushor.2009.09.003

19. Kietzman, J. H., Hermkens, K., McCarthy, I. P., and Silvestre, B. S. (2011), "Social media? Get serious! Understanding the functional building blocks of social media", Business Horizons, Vol. 54, No. 3, pp 241-251.

https://doi.org/10.1016/j.bushor.2011.01.005

20. Lévy, P. (2001), Cyberculture (Electronic mediations). London: University of Minnesota Press.

21. Lincoln, Y.S., and Guba, E.G. (1985), Naturalistic inquiry. Beverly Hills: Sage Publications.

22. Lovink, G. (2011), Networks without a cause: A critique of social media. Cambridge: Polity.

23. Marwick, A. (2013), Status update: Celebrity, publicity, and branding in the social media age, New Haven: Yale University Press.

24. Mcquarrie, E.F., Miller, J., and Phillips, B.J. (2012), “The Megaphone effect: Taste and Audience in Fashion Blogging", Journal of Consumer Research, Vol. 40, No. 1, pp. 136-158. https://doi.org/10.1086/669042

25. McCracken, G. (1985), "The Trickle-down theory revisited”, In Solomon, M.R. (ed.) The psychology of fashion. Lexington, MA: Lexington Books, pp 39-54.

26. Miller, V. (2011), Understanding digital culture. London: Sage Publications.

27. Miles, M. and Huberman, M. (1984), Qualitative data analysis: a sourcebook of new methods. Beverly Hills: Sage Publications.

28. Oliver, P. (2010) Understanding the research process. London: Sage Publications.

29. Pederson, J. (2011), "Metamodernism in Fashion and Style Practice: Authorship and the Consumer", Paper presented at 3rd Global Conference: Fashion Platforms: 
Designing Communication.

30. Pham, M. (2011) "Blog Ambition: Fashion, Feelings, and the Political Economy of the Digital Raced Body", Camera Obscura, Vol. 26, No. 1, pp 1-37. https://doi.org/10.1215/02705346-2010-013

31. Pham, M. (2013), "Susie Bubble is a Sign of The Times", Feminist Media Studies, Vol. 13, No. 2, pp 245-267. https://doi.org/10.1080/14680777.2012.678076

32. Phillips, B. J. and McQuarrie, E. F. (2010), "Narrative and Persuasion in Fashion Advertising", Journal of Consumer Research, Vol. 37, No. 3, pp 368-392. https://doi.org/10.1086/653087

33. Pihl, C. and Sandstorm, C. (2013), "Value Creation and appropriation in social media - the case of fashion bloggers in Sweden", International Journal of Technology Management, Vol. 61, No. 3/4, pp 309 - 323.

34. Poster, M. (1995), The Second Media Age. Cambridge: Polity.

35. Rocamora, A. (2011), "Personal Fashion Blogs: Screens and Mirrors in Digital Self-portraits", Fashion Theory, Vol. 15, No. 4, pp 407-424.

https://doi.org/10.2752/175174111X13115179149794

36. Rocamora, A. (2013), "How New Are New Media? The Case Of Fashion Blogs", In: W. Bartlett, eds. 2013. Fashion Media: Past and Present. London: Bloomsbury Academic. Ch 13.

37. Rose, G. (2012), Visual methodologies: an introduction to the interpretation of visual materials, 2nd ed. London: Sage Publications.

38. Shinkle, E. (2008), Fashion as Photograph: viewing and reviewing images of fashion. New York: Palgrave Macmillan.

39. William, V. (1998), Look at Me: Fashion and Photography in Britain 1960 to the Present. London: The British Council.

40. William, V. (2008), "A Heady Relationship: Fashion Photography and the Museum, 1979 to the Present", Fashion Theory, Vol. 12, No. 2, pp 197-218. https://doi.org/10.2752/175174108X299998 